\title{
The Vacuolar ATPase from Entamoeba histolytica: Molecular cloning of the gene encoding for the B subunit and subcellular localization of the protein
}

\author{
Mayra Gisela Meléndez-Hernández¹, María Luisa Labra Barrios², \\ Esther Orozco ${ }^{1}$ and Juan Pedro Luna-Arias*2
}

Address: ${ }^{1}$ Departmento de Infectómica y Patogénesis Molecular, Cinvestav-IPN, Av. IPN 2508, Col. Zacatenco, CP07360, D. F. México, México and ${ }^{2}$ Departmento de Biología Celular, Cinvestav-IPN, Av. IPN 2508, Col. Zacatenco, CP07360, D. F. México, México

Email: Mayra Gisela Meléndez-Hernández - mayra_smyrna@hotmail.com; María Luisa Labra Barrios - azu_car2000@yahoo.com.mx; Esther Orozco - esther@cinvestav.mx; Juan Pedro Luna-Arias* - juanplunaa@yahoo.com

* Corresponding author

Published: 23 December 2008

BMC Microbiology 2008, 8:235 doi:10.1 I86/147/-2180-8-235
Received: 3 September 2008

Accepted: 23 December 2008

This article is available from: http://www.biomedcentral.com/I47I-2I80/8/235

C 2008 Meléndez-Hernández et al; licensee BioMed Central Ltd.

This is an Open Access article distributed under the terms of the Creative Commons Attribution License (http://creativecommons.org/licenses/by/2.0), which permits unrestricted use, distribution, and reproduction in any medium, provided the original work is properly cited.

\begin{abstract}
Background: Entamoeba histolytica is a professional phagocytic cell where the vacuolar ATPase plays a key role. This enzyme is a multisubunit complex that regulates $\mathrm{pH}$ in many subcellular compartments, even in those that are not measurably acidic. It participates in a wide variety of cellular processes such as endocytosis, intracellular transport and membrane fusion. The presence of a vacuolar type $\mathrm{H}^{+}$-ATPase in E. histolytica trophozoites has been inferred previously from inhibition assays of its activity, the isolation of the Ehvmal and Ehvma3 genes, and by proteomic analysis of purified phagosomes.
\end{abstract}

Results: We report the isolation and characterization of the Ehvma2 gene, which encodes for the subunit B of the vacuolar ATPase. This polypeptide is a $55.3 \mathrm{kDa}$ highly conserved protein with 34 to $80 \%$ identity to orthologous proteins from other species. Particularly, in silico studies showed that EhV-ATPase subunit B displays $78 \%$ identity and $90 \%$ similarity to its Dictyostelium ortholog. A 462 bp DNA fragment of the Ehvma2 gene was expressed in bacteria and recombinant polypeptide was used to raise mouse polyclonal antibodies. EhV-ATPase subunit B antibodies detected a $55 \mathrm{kDa}$ band in whole cell extracts and in an enriched fraction of DNA-containing organelles named EhkOs. The V-ATPase subunit B was located by immunofluorescence and confocal microscopy in many vesicles, in phagosomes, plasma membrane and in EhkOs. We also identified the genes encoding for the majority of the V-ATPase subunits in the E. histolytica genome, and proposed a putative model for this proton pump.

Conclusion: We have isolated the Ehvma2 gene which encodes for the V-ATPase subunit B from the $E$. histolytica clone $A$. This gene has a 154 bp intron and encodes for a highly conserved polypeptide. Specific antibodies localized EhV-ATPase subunit B in many vesicles, phagosomes, plasma membrane and in EhkOs. Most of the orthologous genes encoding for the EhV-ATPase subunits were found in the $E$. histolytica genome, indicating the conserved nature of V-ATPase in this parasite. 


\section{Background}

Entamoeba histolytica is the protozoan parasite which causes human amebiasis. It is estimated that between 40,000 and 100,000 people die annually worldwide from this condition [1]. Four sequential steps have been described during the trophozoite-target cell interaction: 1) adherence, 2) extracellular cytolysis, 3) contact-dependent cytolysis and 4) phagocytosis [2]. Lysis of epithelial cells inside trophozoites requires specific and precise $\mathrm{pH}$ that is provided in different vacuoles [2]. The vacuolar $\mathrm{H}^{+}$ ATPase (V-ATPase) is the key enzyme in many, if not all, acidification processes inside vacuoles. This enzyme is a multisubunit complex that translocates protons across membranes against their electrochemical potential through ATP hydrolysis. The V-ATPase is formed by the $\mathrm{V}_{0}$ complex, corresponding to the integral membrane sector, and the $\mathrm{V}_{1}$ complex that constitutes the globular headpiece responsible for the catalytic activity [3-5]. The VATPase is located in endoplasmic reticulum, secretory vesicles, Golgi vesicles, clathrin-coated vesicles, endosomes, lysosomes, storage vesicles, synaptic vesicles and the central vacuole (in plants and fungi), but it can also be found in plasma membranes [3,4]. V-ATPase also participates in the biosynthetic and endocytic pathways, transmembrane transport of viral contents and toxins, and in coupled transport of small molecules [3-6]. Moreover, V-ATPase is involved in cytosolic $\mathrm{pH}$ regulation, in $\mathrm{Na}^{+}, \mathrm{Ca}^{2+}$ and $\mathrm{Cd}^{2+}$ uptake via $\mathrm{H}^{+}$-driven antiport, in $\mathrm{H}^{+}$-dependent transport of monoamines and $\gamma$-aminobutyrate neurotransmitters carried out by the difference in $\mathrm{H}^{+}$concentration, and in glutamate uptake driven by the membrane voltage [3-6]. Additionally, it is thought that the V-ATPase is the $\mathrm{pH}$ sensor that regulates transport from early to late endosomes. This assumption is supported by the interaction between V-ATPase and the small GTP-binding protein ARF6 and its GDP/GTP exchange factor ARNO in a pH-dependent manner [7].

Several years ago acidification inhibition experiments of pinocytic vesicles with bafilomycin A1 revealed the presence of the vacuolar ATPase in E. histolytica [8]. However, only two genes encoding for E. histolytica ATPase subunits have been cloned: Ehvma1 is an intron-less gene that encodes for the $67 \mathrm{kDa}$ subunit $\mathrm{A}$ of $\mathrm{V}_{1}$ complex [9]. Ehvma3 encodes for an 18.1 kDa polypeptide corresponding to the $c$ subunit of the $\mathrm{V}_{0}$ complex [10]. Recently, proteins related to $\mathrm{V}$-ATPase have been identified by proteomic analysis of purified phagosomes in E. histolytica $[11,12]$. In order to continue with the study of subunits forming the ATPase in this parasite and to investigate their role in phagocytosis, we report here the cloning and characterization of the Ehvma2 gene which encodes for the E. histolytica $\mathrm{B}$ subunit of the $\mathrm{V}_{1}$ complex. We also performed the subcellular location of its encoded protein in trophozoites during phagocytosis.

\section{Results \\ Cloning and characterization of the gene encoding for the subunit $B$ of the vacuolar ATPase of E. histolytica}

A 1,870 bp DNA fragment (amplified using S-Bvac and AS-Bvac primers) was cloned into the pGEM-T-Easy vector. DNA sequencing revealed that cloned DNA contains two open reading frames (ORFs) of 65 (E1, 1-64 nt) and 1,427 bp (E2, 200-1626 nt), separated by a 135 bp noncoding region (I, 65-199 nt) (Fig. 1a). In region I we localized a splicing consensus sequence for nuclear-encoded genes, suggesting that it could be an intron. RT-PCR assays using the primers Bvac-S- 1 and Bvac-AS- 833 gave a $700 \mathrm{bp}$ product, whereas amplification with genomic DNA produced an 833 bp fragment, indicating that Ehvma2 gene (UniProtKB/TrEMBL entry Q4VSM4) contains a $135 \mathrm{bp}$ intron (Fig. 1a, b). Ehvma2 gene from clone A was 100\% identical to the corresponding gene of E. histolytica HM1:IMSS (locus EHI_189850) reported in the E. histolytica genome data bank. It encodes for a predicted 496 amino acid polypeptide of $55.3 \mathrm{kDa}$ and a pI of 4.9. Blast search of the amino acid sequence encoded by Ehvma2 revealed a high degree of conservation with other VATPase B subunits from a number of organisms with an identity from $34 \%$ to $78 \%$ and a similarity varying from $53 \%$ to $90 \%$.

The EhV-ATPase B subunit (EhV-ATPaseB) has three domains (Fig. 1c): Domain I, (aa 26-92) is the beta-barrel domain (Pfam domain PF02874). Domain II (aa 140376 ) corresponds to the core region containing the highly conserved nucleotide binding domain (PF00006). Domain III (aa 393-482) is the domain found in the ATP synthase alpha/beta family (PF00306). The conserved central domain contains the P-loop structure, which forms a flexible loop that interacts with one of the phosphate groups of ATP in $\alpha$ and $\beta$ subunits of F-ATPase, and in V-ATPase subunit A [13]. V-ATPase B subunit from Bos taurus brain cells has a region which works like a P-loop and binds BzATP, an ATP analog [14]. B subunits conserve all residues implicated in the interaction with actin, the nucleotide binding site and the ATP synthase alpha and beta subunits signature. The actin-interaction domain found in EhV-ATPase B subunit was located in the region from $\mathrm{K} 5$ to V48, the BzATP consensus binding site ([IV]Y-P- [EQ]-E-M-I- [QES]) was localized from V140 to Q147 and the ATP synthase alpha and beta subunits signature (P- [SAP]- [LIV]- [DNH]-xxx-S-X-S) was found in the region from P367 to S376 (Fig. 1c). Finally, the EhVATPase B N- and C-terminal regions differed in size and sequence with respect to the corresponding ends of B subunits from other organisms. 
(a)

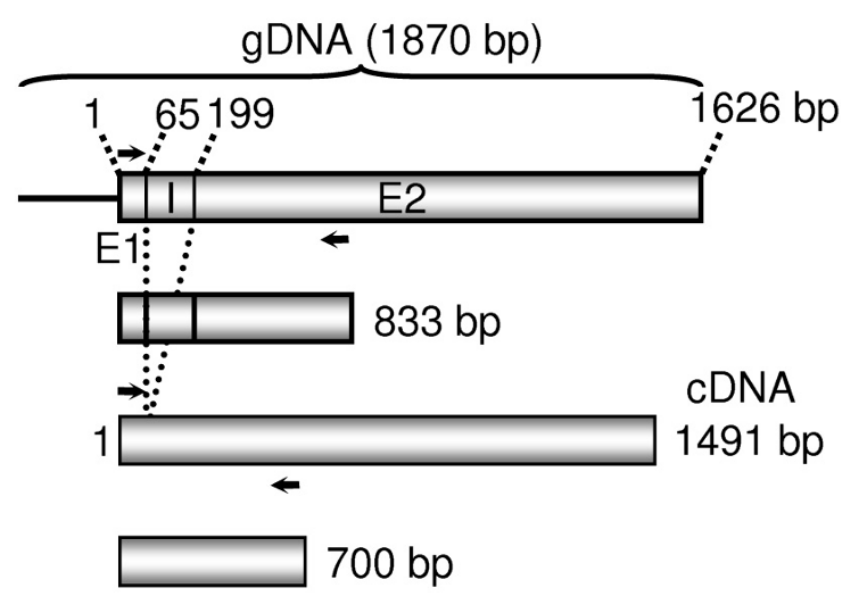

(b)

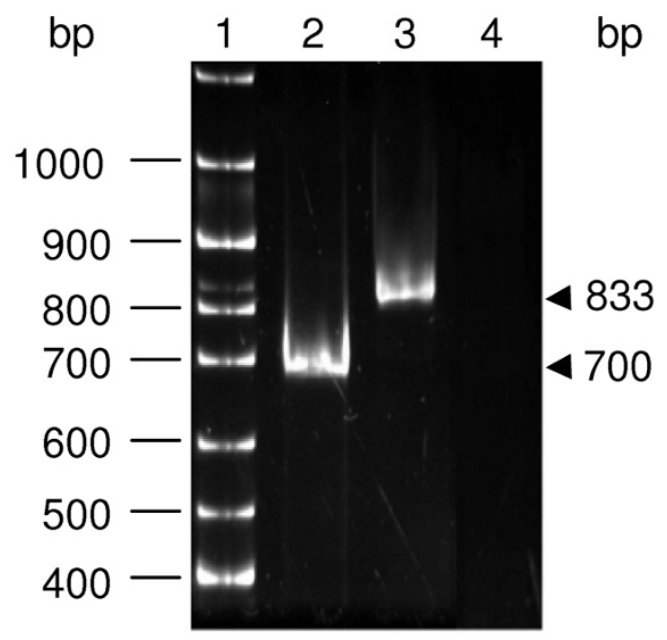

(c)

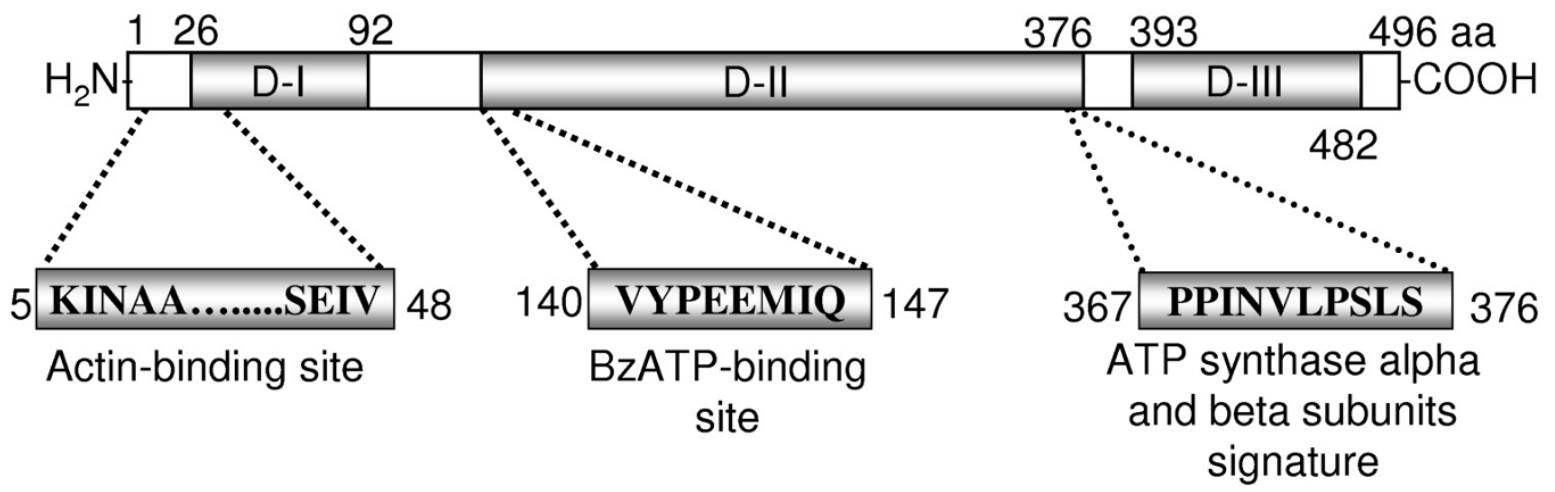

Figure I

Organization of the Ehvma2 gene. (a) Ehvma2 gene is structured by exons EI (I-64 nt) and E2 (200-I,626 nt) separated by an intron (I) of I35 bp (65-199 nt). Arrows show position Bvac-S-I (sense) and Bvac-AS-833 (antisense) primers used in PCR with genomic DNA (gDNA) and RT-PCR. Predicted lengths of DNA amplified from gDNA (833 bp) and from cDNA (700 bp) are also shown. (b) EtBr stained 4\% PAGE gel. Lane I, 100 bp DNA ladder; lane 2, DNA amplified by RT-PCR; lane 3, DNA amplified with gDNA; lane 4, negative control of RT-PCR where no reverse transcriptase was used. (c) Structure of EhVATPaseB showing the beta-barrel domain (D-I), the nucleotide-binding domain (D-II), the C-terminal domain found in the ATP synthase alpha/beta family (D-III), the putative actin-binding site, the BzATP-binding site sequence, and the signature of ATP synthase alpha and beta subunits.

Expression of a specific polypeptide of the $\mathrm{E}$. histolytica vacuolar ATPase subunit B in bacteria

To determine if the $E$. histolytica genome contains sequences related to the V-ATPase B subunit, we performed a BLAST search and found that the V-ATPase A subunit was the only sequence related. It showed 23\% identity and $38 \%$ similarity to EhV-ATPaseB (Fig. 2). The most divergent region between these sequences resides in their N-terminal ends. Thus, we selected a 462 bp region (I81 to V234) of the gene encoding for the V-ATPase subunit B to be cloned in frame into pRSET A vector to express a $21 \mathrm{kDa}$ recombinant His-tagged polypeptide (rEhBvac21) in E. coli (Fig. 3a, lane 3). This polypeptide was purified by immobilized metal affinity chromatogra- 


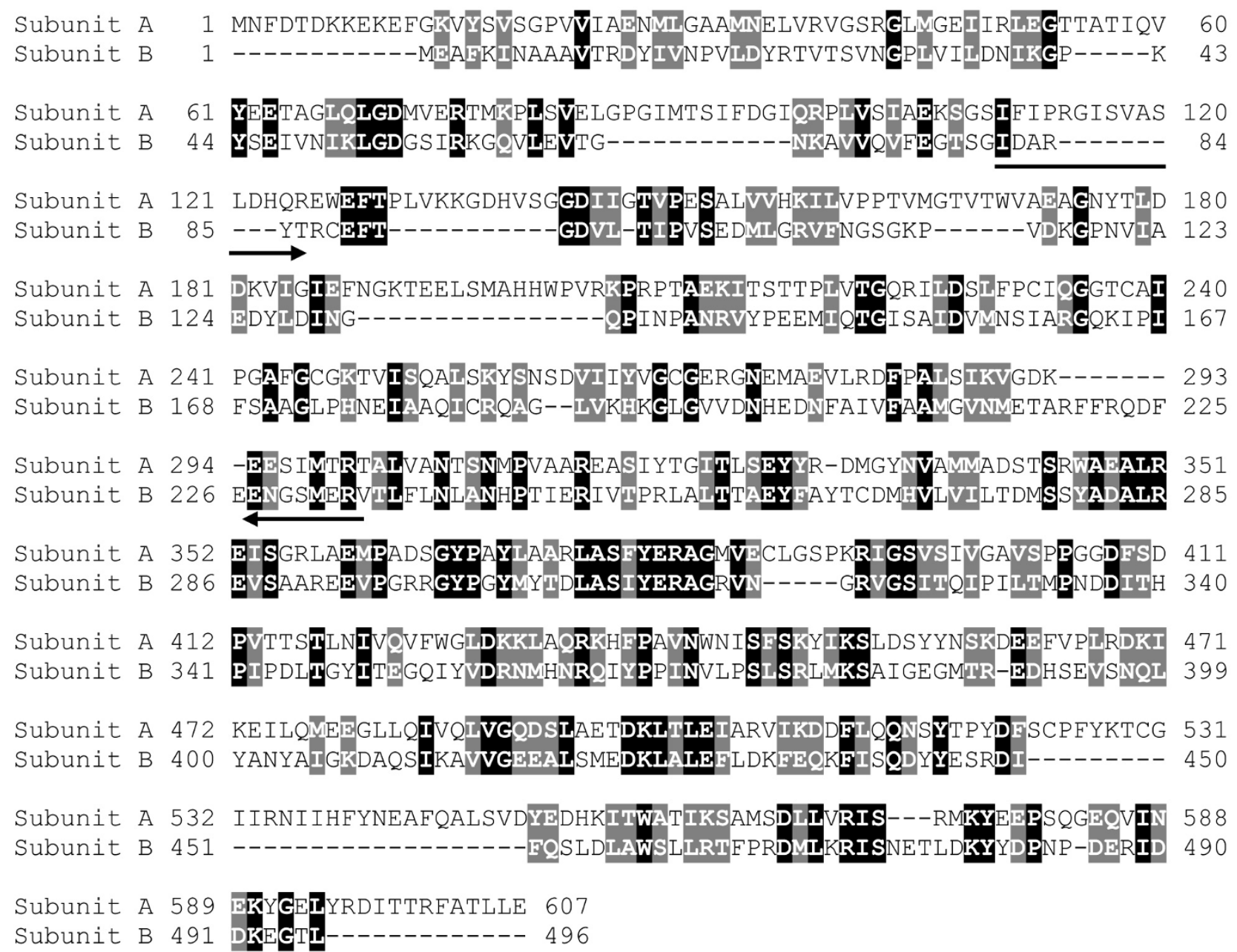

Figure 2

Alignment of polypeptide sequences of subunits A and B of the EhV-ATPase. Alignment was performed using the ClustalW program. Identical amino acids are shown in black boxes. Conserved changes are shown in gray boxes. Numbers correspond to amino acid positions in each polypeptide. Arrows indicate primers Bvac-S-373 and Bvac-AS-833 used to amplify by PCR a 465 bp DNA fragment containing a 154 aa region, which is a EhV-ATPaseB specific region.

phy (IMAC) through a $\mathrm{Ni}^{2+}$-NTA agarose column under denaturing conditions (Fig. 3a, lane 4). In Western blot assays the anti-6His-Tag monoclonal antibodies recognized the induced rEhBvac21 polypeptide band in extracts of $1 \mathrm{mM}$ IPTG induced bacteria (Fig. 3b, lane 3 ) and purified rEhBvac21 (Fig. 3b, lane 4). This result confirms the nature of induced polypeptide. Therefore, rEhBvac21 protein was electroeluted from 12\% SDS-PAGE gels and used to produce mouse polyclonal anti-rEhBvac 21 antibodies that specifically identified rEhBvac2 1 in induced bacteria (Fig. 3c, lane 2), while pre-immune serum did not recognize any bacterial polypeptide (Fig. 3c, lane 1). Mouse polyclonal anti-rEhBvac2 1 antibodies reacted with a 55 kDa band in trophozoite total extracts (Fig. 3d, e, lanes 1), which corresponds to the predicted molecular weight of the full length EhV-ATPase B subunit.

\section{Localization of the subunit B of V-ATPase in E. histolytica trophozoites}

We carried out immunodetection experiments of endogenous EhV-ATPaseB protein using anti-rEhBvac21 antibodies and paraformaldehyde-fixed trophozoites. Through confocal microscopy, antibodies anti-rEhBvac21 located the EhV-ATPase B polypeptide in many small vesicles (Fig. 4a, c, g). The EhV-ATPase B subunit was also observed in EhkOs, but not in nuclei (Fig. 4a, c, and 4g, arrows). Some cells presented the EhV-ATPase B subunit in two EhkOs located in different planes (Fig. 4a, c, 
(a)

(b)

(c)

$\begin{array}{lllll}\mathrm{kDa} & 1 & 2 & 3 & 4\end{array}$

$\begin{array}{lllll}\mathrm{kDa} & 1 & 2 & 3 & 4\end{array}$
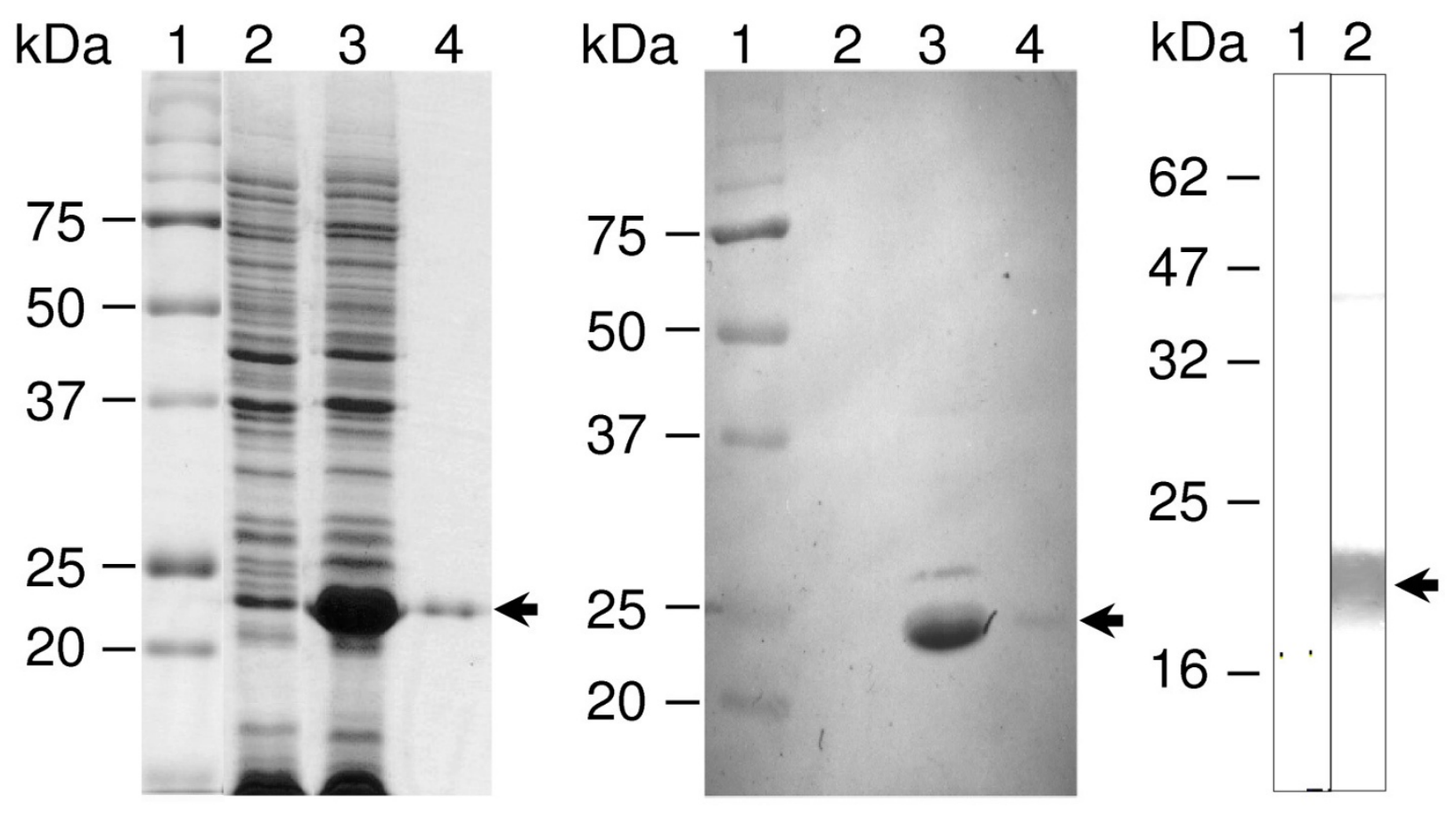

(d)

(e)
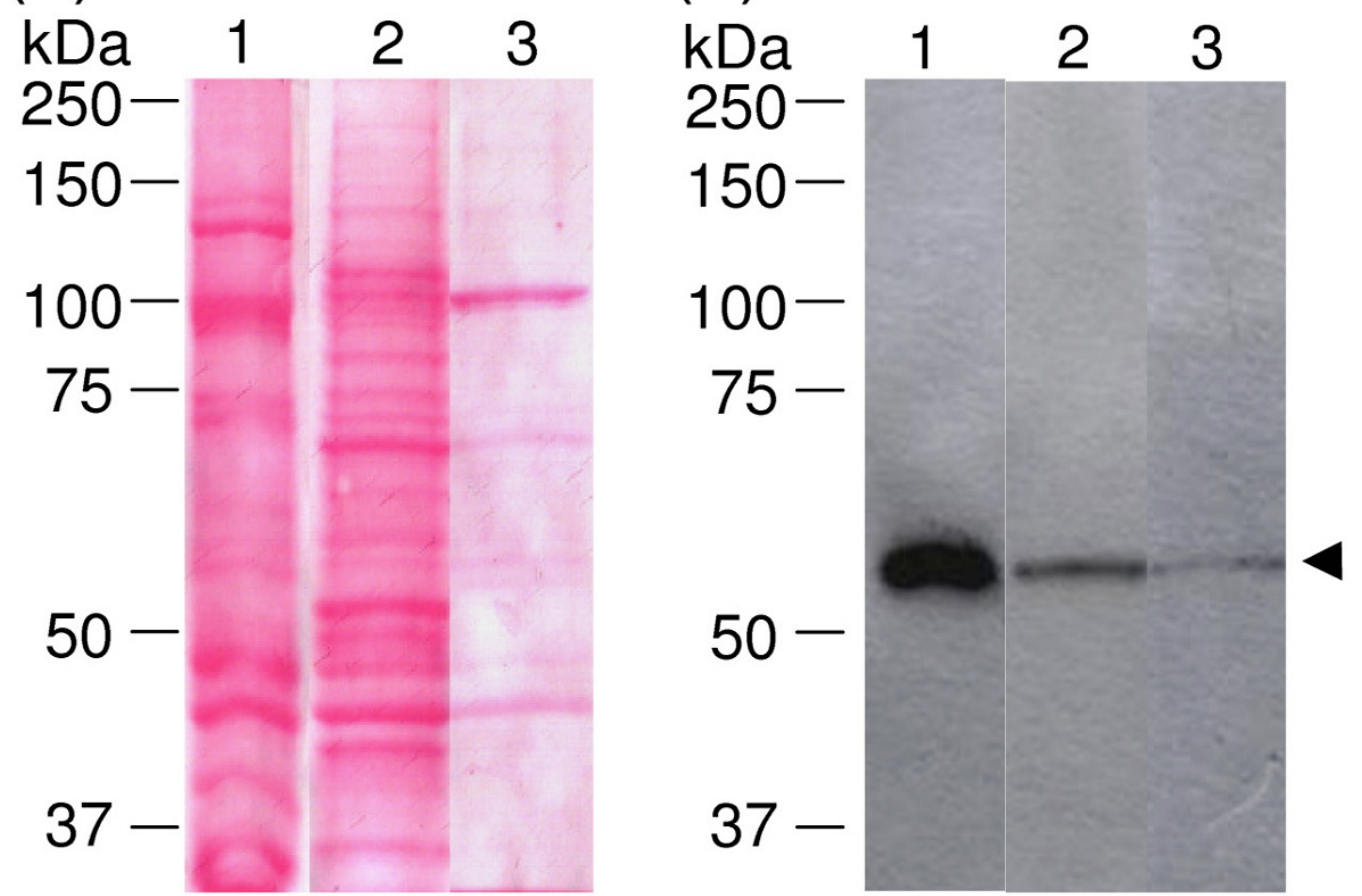

Figure 3 (see legend on next page) 
Figure 3 (see previous page)

Expression of a recombinant $2 \mathrm{l} \mathrm{kDa}$ polypeptide (rEhBvac2 I) from the EhV-ATPase B subunit and immunodetection of the endogenous protein by Western blot assays. rEhBvac2I polypeptide was IPTG induced in bacteria and purified through a Ni2+-NTA-agarose column as described in Methods. (a) Coomassie Blue stained I5\% SDS-PAGE gel. Lane I, protein molecular weight markers; lane 2, non-induced bacteria; lane 3, induced bacteria; lane 4, purified rEhBvac2 I polypeptide. (b) Western blot assay of gel shown in (a), using anti-6His-tag monoclonal antibodies and horseradish peroxidase-conjugated anti-mouse IgG secondary antibodies $(1: I, 000)$, and revealed as described. (c) Western blot of purified rEhBvac2 $I$ polypeptide using: lane I, mouse pre-immune serum or lane 2, mouse polyclonal anti-rEhBvac2 I antibodies (I:I,000), and horseradish peroxidase-conjugated anti-mouse lgG secondary antibodies $(I: I, 000)$. (d) Ponceau stained nitrocellulose membrane of proteins (see Methods) separated by I0\% SDS-PAGE. Lane I, whole trophozoites; lane 2, soluble fraction; lane 3, EhkO-enriched fractions. (e) Immunodetection of proteins shown in (d), with mouse polyclonal anti-rEhBVac2 I antibodies $(\mathrm{I}: 20,000)$ and horseradish peroxidase-conjugated goat anti-mouse IgG secondary antibodies $(\mathrm{I}: 3,000)$ using the ECL Plus detection kit as described. Arrow shows the rEhBvac2 I polypeptide. Arrow-head indicates the endogenous V-ATPse B subunit.

arrows). EhkOs were also stained with propidium iodide (PI) (Fig. 4b, d, and 4h, arrows) indicating they are DNAcontaining organelles [15]. Nuclei did not appear PI stained in figure 4 because they were located in different planes (not shown) to those containing EhkOs. Colocalization of green and red fluorescent signals is also shown (Fig. 4e, i, arrows), corroborating that DNA and EhVATPase $\mathrm{B}$ subunit are in the same organelles. As a negative control we incubated cells without primary antibodies (Fig. 4k). Light microscopy images showed cellular integrity (Fig. 4f, j, and 4l). Immunolocalization of EhVATPase B subunit in EhkOs was confirmed by Western blot of an EhkO-enriched fraction prepared as described, which detected the $55 \mathrm{kDa}$ band found in total protein extracts (Fig. 3d, e, lanes 3). We also determined the VATPase activity in this fraction (that was kept at $-70^{\circ} \mathrm{C}$ ) using the method described in [16], obtaining a specific activity of 6.04 nanomoles of phosphate produced in one hour per microgram of protein at $37^{\circ} \mathrm{C}$.

\section{The E. histolytica vacuolar ATPase subunit B was found widely distributed in all cellular membranes in phagocytic trophozoites}

In confocal microscopy experiments of trophozoites during the phagocytosis of red blood cells (RBCs) we observed a wide distribution of EhV-ATPaseB protein through all the trophozoite membranes with the exception of nuclear membrane (Fig. 5). EhV-ATPaseB was found surrounding many vesicles of different sizes (Fig. $5 \mathrm{i}$, arrows) and in plasma membrane (Fig. 5a, e, i, arrowheads). Some areas concentrated huge amounts of the protein located in cytoplasm (Fig. 5i, asterisk). The subunit B of EhV-ATPase was detected in phagocytic vesicles surrounding RBCs as expected (Fig. 5a, e, i, dotted arrows), confirming the presence of subunit B in phagocytic vacuoles as it has been previously reported [11]. However, our results showed no difference in the distribution of the subunit B of the vacuolar ATPase at the different times of phagocytosis tested. A negative control using preimmune serum was also carried out with no fluorescent signal (Fig. 5k). Nuclei were stained in red (Fig. 5b, f), and a merge of red and green fluorescent signals was also performed (Fig. 5c, g). It is noteworthy that subunit B was accumulated in huge amounts in the phagocytic mouth of a trophozoite ingesting a red blood cell (Fig. $5 e)$. To determine if the Ehvma2 gene was being expressed in trophozoites during erythrophagocytosis, we carried out RT-PCR experiments that showed that this gene is being expressed (Fig. 5m). As control we used the actin gene that showed that it is also being expressed during this process (Fig. 5n).

\section{Putative subunits of the vacuolar ATPase found in the E. histolytica genome}

We searched for the orthologous genes encoding for all the subunits of vacuolar ATPase in the E. histolytica genome database [17]. A BLAST search was done using the genes encoding for the vacuolar ATPase polypeptides from Saccharomyces cerevisiae. E. histolytica has orthologous genes encoding for all subunits of $V_{1}$ complex of the vacuolar ATPase (Table 1). The corresponding Entamoeba genes were designated by the nomenclature used for the yeast vacuolar ATPase. Ehvma1 gene (Q24802 entry) encoded for the subunit A. Subunit B is encoded by Ehvma2 gene (Q4VSM4). We also found a pseudogene related to Ehvma2, denoted as $\Psi$ Ehvma2, that was located at a different scaffold. Subunits C, F, G and H are encoded by Ehvma5, Ehvma7, Ehvma10, and Ehvma13 genes, respectively. On the other hand, we found two genes (Ehvma8-1 and Ehvma8-2) encoding for the putative subunit D located in different scaffolds, which predict proteins sharing a $98 \%$ identity. Subunit $\mathrm{E}$ is also encoded by two genes, Ehvma4-1 and Ehvma4-2, which are arranged in tandem on the same DNA strand in the E. histolytica genome (scaffold 9), and encode for proteins with a 51\% identity between them. Orthologous genes encoding for the probable subunits of $\mathrm{V}_{0}$ complex were also found in the E. histolytica genome with the exception of $c^{\prime}$ and e subunits. V- 

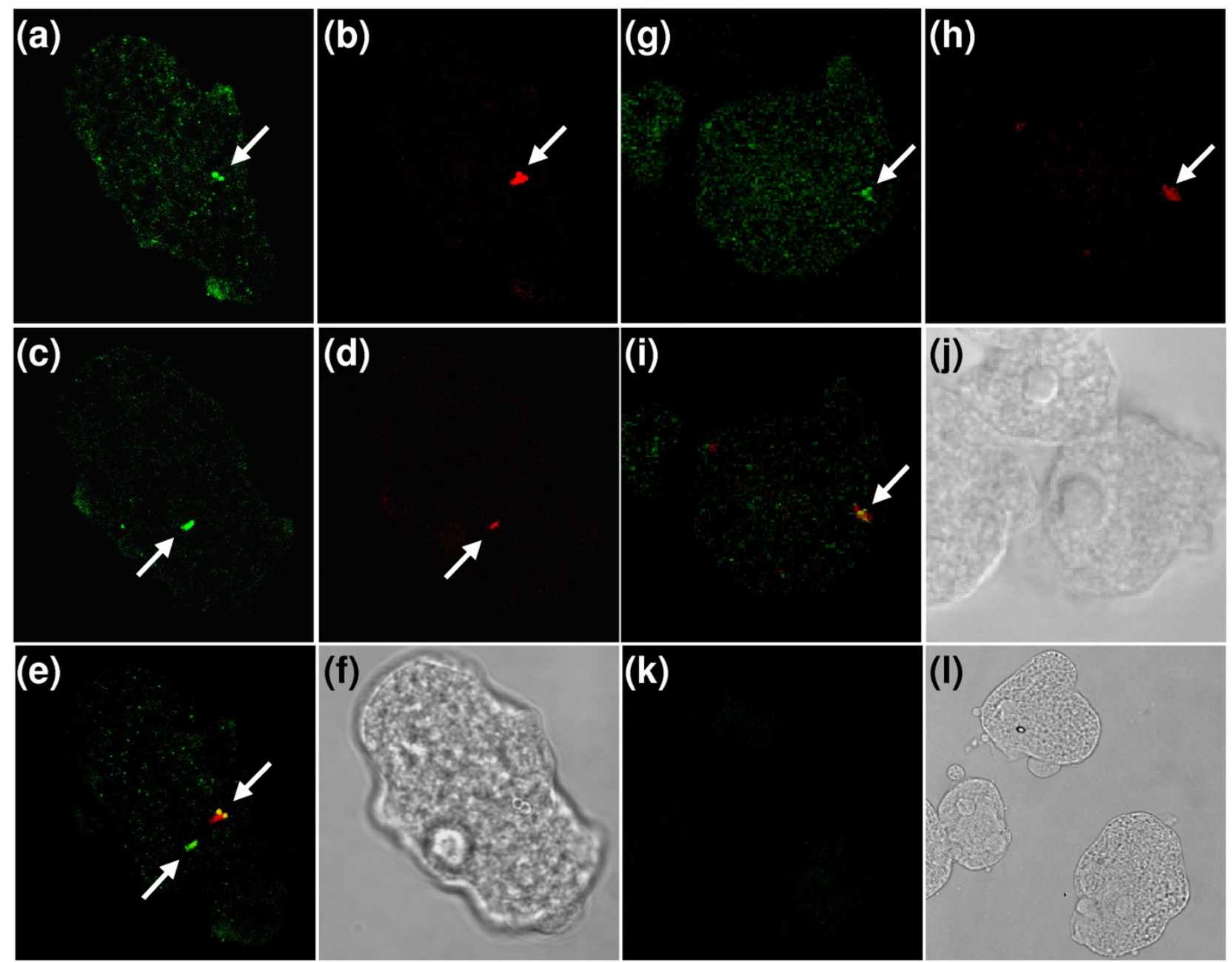

\section{Figure 4}

The EhV-ATPase B subunit colocalized with the DNA-containing organelles (EhkOs). Trophozoites were fixed, permeabilized and incubated with anti-rEhBvac2 I antibodies. Then, they were incubated with FITC-labeled goat anti-mouse antibodies and observed through a laser confocal microscope. (a, c) Immunodetection of EhV-ATPase B found within two different planes of the same cell (green channel). (b, d) Sections observed in (a) and (c), respectively, showing the DNA staining (red channel). (e) Merge of green and red fluorescence emissions shown in (a) through (d) which correspond to the two cellular planes mentioned before. ( $f$ ) Cell from panels (a)-(e) observed by light microscopy. (g) EhV-ATPaseB localization in a section of another cell observed in green channel. (h) Same plane as (g), but observed in red channel. (i) Merge of fluorescence signals emitted in $(\mathrm{g})$ and $(\mathrm{h})$. (j) Cells of panels $(\mathrm{g})$-(i) observed by light microscopy. (k) Cells incubated only with secondary antibodies as a negative control and observed in green channel (maximal projection). (I) Cells of negative control observed by light microscopy. Arrows indicate EhkOs.

ATPase a subunit is encoded by two genes, Ehstv1 and Ehvph1. The former is encoded at a single locus. The latter has two identical copies located at two different scaffolds. Ehstv1 and Ehvph1 predicted for putative proteins with $51 \%$ identity. Subunits c and c" are putatively encoded by Ehvma3 (Q24810 entry) and Ehvma16, respectively, and their polypeptides have $25 \%$ identity. A Blast search in the E. histolytica genome using the $S$. cerevisiae $c^{\prime}$ protein sequence (P32842 entry) as query reported the same genes mentioned above, but showing a lesser identity than that shown when comparing with $S$. cerevisiae subunits $\mathrm{c}$ and $\mathrm{c}^{\prime \prime}$ (data not shown), suggesting that $E$. histolytica genome lacks an orthologous $c^{\prime}$ subunit encoding gene. Finally, subunit $\mathrm{d}$ is encoded by a single copy of the Ehvma6 gene. Noteworthy all the V-ATPase subunit encoding genes are located in different scaffolds. 

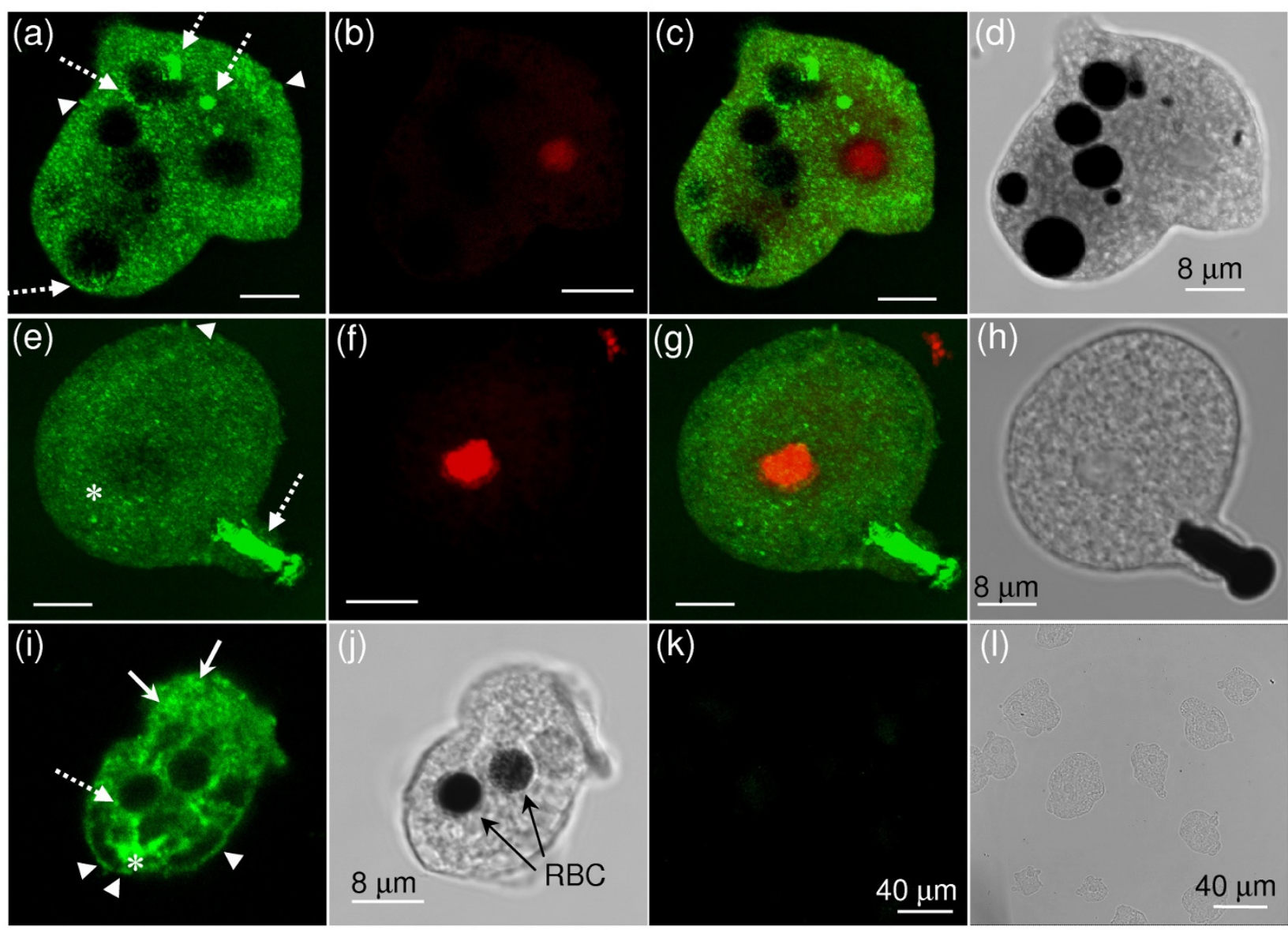

(m)

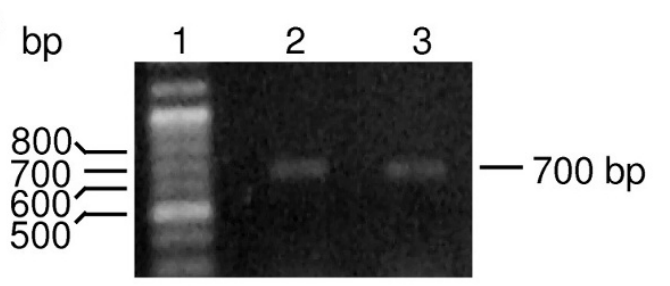

(n)

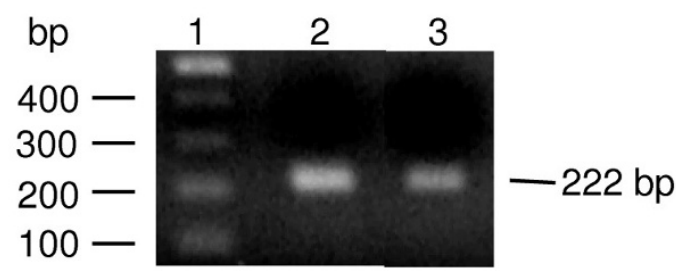

Erythrophagocytosis: $\quad 0 \quad 30 \quad \mathrm{~min}$

$0 \quad 30 \quad \min$

\section{Figure 5}

Localization of EhV-ATPase B subunit in trophozoites during RBC phagocytosis. Trophozoites were incubated with diamine bencidine-stained RBCs for 5 min $(\mathrm{a}-\mathrm{j})$, washed with PBS and fixed with paraformaldehyde. Then, cells were treated with anti-rEhBvac2 I antibodies and FITC-labeled goat anti-mouse antibodies, and observed through a laser confocal microscope as described. (a, e, i). Immunodetection of EhV-ATPaseB observed in green channel. (b, f) Cells observed in red channel. (c, g) Merge of fluorescent signals observed in (a, b) and (e, f), respectively. (d, h, j, l) Cells observed by light microscopy. (k) Cells incubated only with secondary antibodies as negative control and observed in green channel. (m, $n$ ) Electrophoresis in $1.0 \%$ agarose gels of RT-PCR gene products of Ehvma2 $(\mathrm{m})$ and actin $(\mathrm{n})$ in trophozoites at 0 min (lane 2) and 30 min (lane 3) of erythrophagocytosis. Lane I, 100 bp size molecular ladder. Arrowheads, EhV-ATPaseB found in plasma membranes. Arrows, EhV-ATPaseB polypeptide found in cytoplasmic vesicles. Dotted arrows, EhV-ATPaseB polypeptide found in phagocytic vacuoles containing RBCs. Asterisks, huge concentrations of EhV-ATPaseB found within trophozoites. 
Table I: Genes encoding for putative subunits of the vacuolar ATPase of Entamoeba histolytica

\begin{tabular}{|c|c|c|c|}
\hline Subunit & Gene & Locus & Function\# \\
\hline $\mathrm{A}(\mathrm{Q} 24802)^{*}$ & Ehvmal & EHI_0430I0T & Catalytic site and regulation \\
\hline \multirow[t]{2}{*}{ B (Q4VSM4)* } & Ehvma2 & EHI_I89850थ & Non-catalytic site \\
\hline & $\psi E$ Ehvma2 & $122.00032 \S$ & Involved in targeting? \\
\hline C & Ehvma5 & EHI_059840ף & Assembly and activity \\
\hline \multirow[t]{2}{*}{$\mathrm{D}$} & Ehvma8-I & EHI_056390٪ & Assembly and activity \\
\hline & Ehvma8-2 & $202.00016 \S$ & \\
\hline \multirow[t]{2}{*}{$\mathrm{E}$} & Ehvma4-I & $9 . \mathrm{t} 00012 \S$ & Assembly and activity \\
\hline & Ehvma4-2 & $9 . \mathrm{t} 000 \mathrm{I} 3 \S$ & \\
\hline $\mathrm{F}$ & Ehvma7 & EHI_007940爪 & Assembly and activity \\
\hline G & Ehvmalo & $94 . t 00029 \S$ & Assembly and activity \\
\hline $\mathrm{H}$ & Ehvmal3 & $215.00004 \S$ & Activity, but not assembly \\
\hline \multirow[t]{2}{*}{$\mathrm{a}$} & EhvphI & $\begin{array}{l}\text { EHI_074020爪 } \\
417 . t 0000 \mid \S\end{array}$ & $\mathrm{H}+$ transport, assembly, and targeting \\
\hline & Ehstvl & EHI_I07280爪 & \\
\hline c (Q24810)* & Ehvma3 & EHI_059840爪 & $\mathrm{H}+$-transport; DCCD-binding site \\
\hline$c^{\prime \prime}$ & Ehvmal6 & $289 . \mathrm{t} 00003 \S$ & $\mathrm{H}+$ transport \\
\hline$d$ & Ehvmab & $|6| . t 0000 \mid \S$ & Activity and assembly \\
\hline
\end{tabular}

*UniProtKB/TrEMBL Accession number.

TLocus name assigned at Pathema (Bioinformatics Resource Center; http://pathema.jcvi.org/cgi-bin/Entamoeba/PathemaHomePage.cgi). \$Locus with its provisional names in the E. histolytica genome project at The J. Craig Venter Institute.

\#Function was assigned based on reference [5].

\section{Discussion}

The Ehvma2 gene encoding for the B subunit of V-ATPase is highly conserved (Fig. 1c). The protein was located in cytoplasm (showing punctate and diffuse patterns), plasma membrane, vacuolar membrane and in EhkOs (Fig. 4 and Fig. 5). Labeling in cytoplasm could correspond to free $V_{1}$ sectors and to V-ATPase complexes found in small fluorescent vesicles which might be lysosomes $[18,19]$. In yeast cells, the RAVE complex mediates the reversible dissociation between the $\mathrm{V}_{1}$ and $\mathrm{V}_{0}$ complexes by binding to peripheral stalk subunits (C or E and $G$ ) $[20,21]$, that is considered as one of the mechanisms controlling V-ATPase activity [20-22]. This event seems to be regulated by the cellular environment as in yeast in response to glucose depletion [23]. The gene encoding for the Skp1 subunit of the RAVE complex is found in the $E$. histolytica genome (there are four gene sequences encoding for this subunit in Pathema: EHI_118670, EHI_174130, EHI_066770 and EHI_174180), suggesting a similar V-ATPase regulation mechanism in this parasite.

On the other hand, the V-ATPase B subunit found in the E. histolytica plasma membrane (Fig. 5) could indicate that the V-ATPase complex is located there and has a role in tissue invasion in a similar process of metastasizing cells that increase the acidification of the extracellular fluid to produce the destruction of normal tissue and facilitate invasion [3]. Moreover, it could be involved in the transport of diverse solutes in a similar way as it has been described for Plasmodium [24]. It is noteworthy the subunit B localization in EhkOs (Fig. 4), which are cytoplasmic DNA-containing organelles of unknown function $[15,25]$. EhkOs carry EhTBP [26], EhC/EBP [27], and Ehp53 [28] transcription factors, and the EhPFO enzyme [29], but their roles in EhkOs remain to be determined. Another cytoplasmic DNA-containing organelle described in this parasite is the crypton, which harbors the chaperonin Hsp60 $[19,30]$.

Mitosomes, which are DNA-lacking organelles, also contain the chaperonin Cpn60 and are considered as mitochondrial remnants [31]. Mitosomes have also been found in other organisms [32-34]. EhkOs and cryptons could be similar organelles as they carry DNA. However, EhkOs and mitosomes are clearly different [35]. A possible role for the V-ATPase located in EhkOs could be the ATP synthesis using the membrane-bound $\mathrm{H}^{+}$- translocating inorganic pyrophosphatase $\left(\mathrm{H}^{+}-\mathrm{PPase}\right)$ activity found in some organelles in trophozoites [36]. Alternatively, VATPase could be pumping out $\mathrm{H}^{+}$as a consequence of the $B$ subunit localization towards the lumen of these organelles (Fig. 4), in order to keep $\mathrm{pH}$ regulated and avoid degradation of their content.

RBCs ingestion by trophozoites revealed a clustering process of EhV-ATPase B subunit in the vicinity of phagosomes after 5 min of phagocytosis (Fig. 5). The principal route of V-ATPase delivery to phagosomes in D. discoideum is by fusion with pre-existing acidic endosomal vesicles, prior to their content delivery into phagosomes [37]. A similar process might be occurring in Entamoeba, where lysosomes could be stored in the cytosol prior to their fusion with phagosomal vacuoles. During erythrophagocytosis a pre-phagosomal vacuole (PPV) containing Rab5 and 
Rab7A proteins is gradually acidified by fusion with lysosomes. During the first 5-10 min Rab5 is dissociated from PPVs, and digestive proteins are transported from PPVs to phagosomes via Rab7A-mediated vesicular transport $[38,39]$. Although this process needs more studies to identify all proteins involved, V-ATPase should be released during PPV maturation. In addition, interactions of $\mathrm{V}$ ATPase to cytoskeleton through subunits B and C, which are able to bind actin, are essentials for its proper function. For example, the osteoclast subunit $\mathrm{B}$ is responsible for microfilaments-V-ATPase interactions [40]. The putative actin-binding domain that was found in EhV-ATPase subunit B suggests that this process is conserved in this parasite (Fig. 1).

In eukaryotic cells the $\mathrm{V}_{1}$ complex is formed by the subunits $\mathrm{A}_{3} \mathrm{~B}_{3} \mathrm{CDEFG}_{2} \mathrm{H}_{1-2}$ and the $\mathrm{V}_{0}$ complex by subunits $\mathrm{ac}_{4} \mathrm{C}^{\prime} \mathrm{c} " \mathrm{de}$ [3-5]. Based on the genes found in the E. histolytica genome, we propose a putative model for the structure of the vacuolar ATPase in this parasite (Fig. 6). The $\mathrm{V}_{0}$ complex might be composed of a ring of five or six proteolipid subunits (four c subunits and either one or two c" subunits, respectively) and one molecule of each a and d subunits. Remarkably, E. histolytica V-ATPase lacks subunits $e$ and ' c'. However, the existence of non-related proteins to e and c' subunits that could evolve separately very early in evolution in Entamoeba is possible. It is important to note that the stoichiometry of the E and G strong interaction is not well established yet. A relationship of two G molecules per one E molecule was assumed, however recent data support that in V-ATPase, G and E subunits are present in more than one copy and thus two peripheral stalks connecting $\mathrm{V}_{1}$ to $\mathrm{V}_{0}$ could exist [41].

Most of the subunits of the E. histolytica V-ATPase are encoded by single genes, excepting for subunits D, E, and a, which are encoded by two genes in each case (Table 1). In the case of the subunit $\mathrm{E}$, two $\mathrm{E}$ isoforms have been

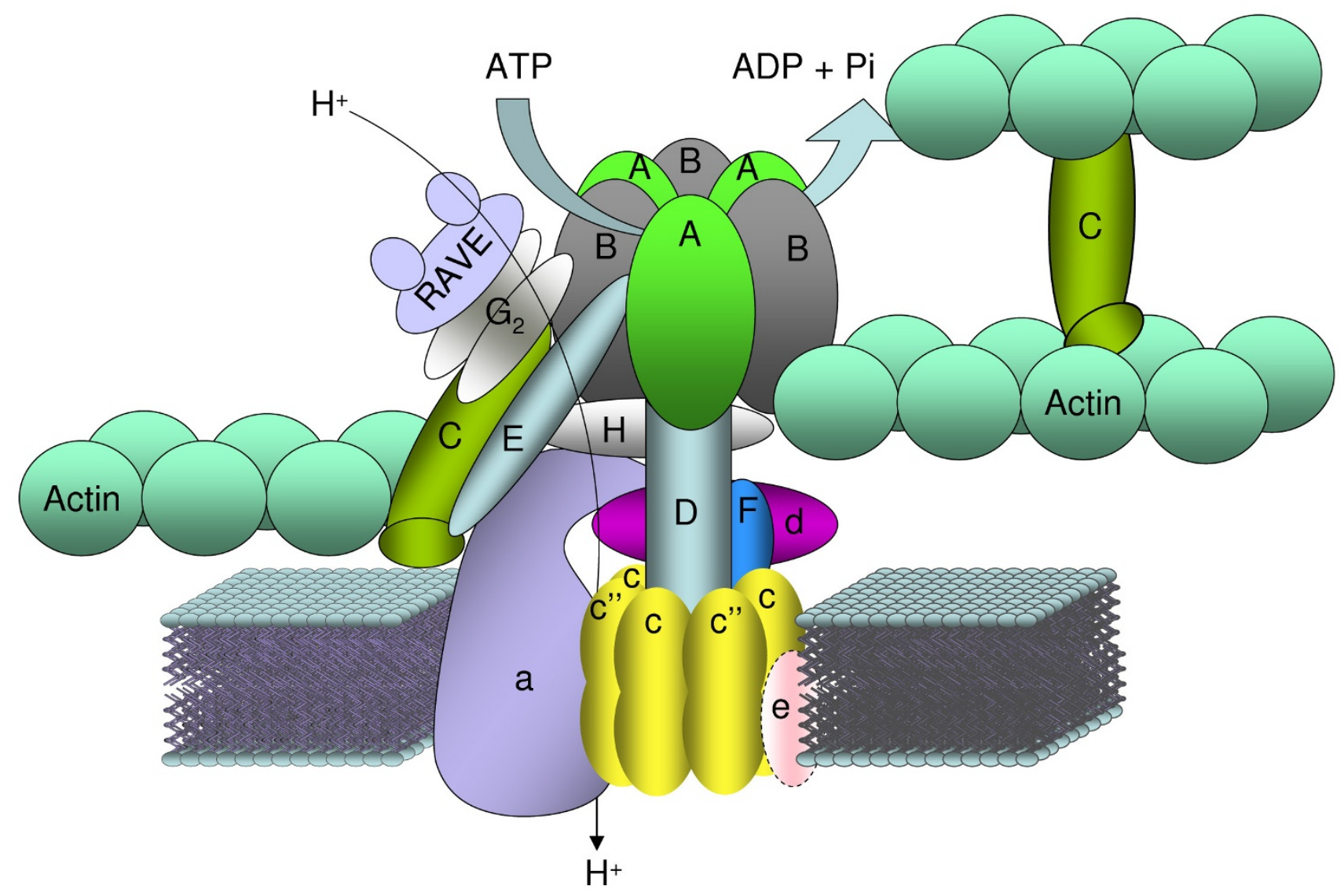

\section{Figure 6}

Hypothetical model of the structure of the vacuolar ATPase of Entamoeba histolytica. The Vacuolar ATPase of E. histolytica is a well conserved protein complex, with the exceptions of subunits $c^{\prime}$ and e, which have not conserved counterparts in this parasite. The structure shown is according to that described in [3,5] and based on data from Table I. Subunit e that was not found in the $E$. histolytica genome is surrounded by a dotted line. 
found in mouse [6], and three in Arabidopsis [42]. Several pea epicotyls V-ATPases isoenzymes exhibiting different ratios of E1 and E2 isoforms have been purified, exhibiting differences in their $\mathrm{Km}$ and Vmax of ATP hydrolysis, and different tissue distribution in the whole plant [43]. Yeast has two subunit a isoforms: 1) Vph1p, which is targeted to the vacuolar membrane, and 2) Stv1p which is targeted to the late Golgi apparatus [44]. Mammals have four genes encoding for different subunit a isoforms, often showing cell-type or tissue-specific locations [5]. A special case is Paramecium, which contains 17 a subunit isoforms, which provide a specific location and function for V-ATPase in at least seven different compartments [45]. Thus, E. histolytica could have at least two V-ATPase isoforms, one distributed in vacuoles, and the other in the Golgi apparatus that could be more primitive in trophozoites than those from other systems due to the lack of a typical Golgi structure [46-48]. More studies are needed to elucidate the V-ATPase role in the physiology of $E$. histolytica trophozoites.

\section{Conclusion}

We cloned the Ehvma2 gene which encodes for the highly conserved V-ATPase B subunit. This protein was immunolocated in EhkOs, in plasma membrane, vesicles, phagocytic vacuoles, and also in the cytoplasm. Most of the orthologous genes encoding for the V-ATPase subunits were also identified in the E. histolytica genome showing that this EhV-ATPase is a highly conserved complex. The in silico analysis of the genes encoding for the V-ATPase subunits in the E. histolytica genome revealed that the $\mathrm{V}_{1}$ complex has all the eight subunits found in V-ATPases. However, the $\mathrm{V}_{0}$ complex lacks the subunits e and c'.

\section{Methods}

\section{E. histolytica cultures}

Trophozoites of E. histolytica clone A were axenically cultured in TYI-S-33 medium at $37^{\circ} \mathrm{C}$ and harvested during the exponential growth phase as described [49]. For EhkOs purification, the medium was supplemented with $2 \mu \mathrm{Ci} / \mathrm{ml}$ [methyl-3 $\mathrm{H}$ ]-Thymidine (Amersham) for $48 \mathrm{~h}$ [50].

\section{Search of V-ATPase genes in the E. histolytica genome database}

A search of V-ATPase genes was performed in the E. histolytica genome databases at The Sanger Institute http:// www.sanger.ac.uk and The J. Craig Venter Institute http:// www.jcvi.org. As query, we used the subunit polypeptide sequences of the vacuolar ATPase of $S$. cerevisiae, and the WU-BLAST version 2.0 program and BLOSUM62 matrix. The UniProt Knowledgebase (UniProtKB)/TrEMBL entries used were P17255 (subunit A), P16140 (subunit B), P31412 (subunit C), P32610 (subunit D), P22203 (subunit E), P39111 (subunit F), P48836 (subunit G), P41807 (subunit H), P37296 (subunit a), P25515 (subunit c), P32842 (subunit c'), P23968 (subunit c"), P32366 (subunit d), and Q3E7B6 (subunit e). Obtained DNA sequences were translated to proteins with the Translate tool at the ExPASy Proteomics Server http:// www.expasy.org. Blast search for each of the Entamoeba polypeptide sequences was done with BLASTP 2.2.14 algorithm in The UniProt Knowledgebase at the ExPASy Proteomics server of the Swiss Institute of Bioinformatics and BLOSUM62 matrix. Alignments were performed with ClustalW version 1.83 algorithm at the European Bioinformatics Institute (EBI, http://www.ebi.ac.uk/Tools/ clustaw2/index.html).

\section{Cloning of the Ehvma2 gene encoding for the subunit B of the E. histolytica vacuolar ATPase}

Based on the nucleotide sequence of the putative Ehvma2 gene found in the E. histolytica genome databases, we designed the primers S-Bvac (sense): 5'-ATGTTATTGTATTAAGACTTTTTAATT-3', and AS-Bvac (antisense): 5'TATAAGGTTCCTTCTTTGTCGT-3' to amplify a $1.87 \mathrm{~kb}$ DNA fragment using $50 \mathrm{ng}$ of total DNA as a template, and $400 \mu \mathrm{M}$ of each dNTP, $2.5 \mathrm{mM} \mathrm{MgCl} 2,300 \mathrm{nM}$ of each primer and $2 \mathrm{U}$ of Taq DNA polymerase (Invitrogen). PCR conditions were $94^{\circ} \mathrm{C}$ for $5 \mathrm{~min}, 30$ cycles of $94^{\circ} \mathrm{C}$ for $30 \mathrm{~s}, 57^{\circ} \mathrm{C}$ for $30 \mathrm{~s}$ and $72^{\circ} \mathrm{C}$ for $90 \mathrm{~s}$, and $72^{\circ} \mathrm{C}$ for 10 $\mathrm{min}$. Amplified DNA was cloned into the pGEM-T-Easy vector (Promega) to generate pGEM-T-Easy-Bvac plasmid. Sequencing of cloned DNA was carried out using gene specific primers and the Big Dye Terminator kit version 2.0 in an Automated DNA Sequencer (310 Genetic Analyzer, Applied Biosystems) in the Sequencing Nucleic Acid Core Facility at Cinvestav-IPN.

\section{RT-PCR}

Total RNA was isolated from trophozoites using TRIzol reagent (Invitrogen) and reverse transcription was carried out with 200 U of SuperScript II reverse transcriptase (Invitrogen) and $40 \mathrm{U}$ of SUPERase-in RNAse inhibitor (Ambion) according to manufacturers' instructions and $1 /$ 6 of reaction volume was used for DNA amplification by PCR with Bvac-S-1 (5'-ATGGAAGCTTTCAAAATT-3') sense and Bvac-AS-833 (5'-CTTTCCATAGAACCATTTTC3') antisense primers using the PCR conditions described above. RT-PCR products were separated on a 4\% PAGE gel in $1 \times$ TBE $\left(90 \mathrm{mM}\right.$ Tris, $90 \mathrm{mM} \mathrm{H}_{3} \mathrm{BO}_{3}$, and $2 \mathrm{mM}$ EDTA, $\mathrm{pH}$ 8.3), stained with $0.05 \%(\mathrm{w} / \mathrm{v})$ ethidium bromide (EtBr), visualized with a UV transilluminator, and images were processed with a Gel Documentation System (BioRad). For RT-PCR analysis of Ehmav2 and actin genes in trophozoites during RBCs erythrophagocytosis, we proceeded as described bellow, but no fixative agents were employed. For actin gene we used primers actin-sense 5'AGCTGTTCTTTCATTATATGC - 3 ' and actin-antisense 5'TCTCTTTCAGCACTAGTGGT-3', and used a Tm of $54^{\circ} \mathrm{C}$. 


\section{Expression and purification of a recombinant fragment polypeptide of E. histolytica V-ATPase subunit B in Escherichia coli}

To express a specific region of EhV-ATPaseB, we amplified by PCR (using the conditions mentioned above) a 478 bp DNA fragment (containing a 465 bp DNA encoding for a 154 aa polypeptide of EhV-ATPaseB and the translation stop signal). The primers used were Bvac-S-373 (5'CGGGATCCGGTATTGATGCACGTTATAC-3') sense and Bvac-AS-833 (5'-CCCAAGCTTTTATCTTTCATAGAACCATTTTC-3') antisense, which contained the BamHI and HindIII restriction sites at their 5 ' ends, respectively. Then, the amplified DNA was cloned into pRSET A vector (Invitrogen) to generate the recombinant pRSET-EhBvac465 plasmid. Recombinant protein expression was induced with $1 \mathrm{mM}$ IPTG in E. coli BL21(DE3) pLysS (Invitrogen). N-terminal His-tagged recombinant EhBvac $21 \mathrm{kDa}$ (rEhBvac21) polypeptide was purified under denaturing conditions by IMAC using a $\mathrm{Ni}^{2+}$-NTA agarose column (Qiagen), following the manufacturer's protocol. Purification of rEhBvac21 polypeptide was improved by electroelution from preparative 15\% SDS-PAGE gels.

\section{Generation of mouse polyclonal antibodies against the rEhBvac2 I polypeptide and Western blot assays}

Specific antibodies against EhV-ATPaseB were generated in BALB/c mice by immunization of $100 \mu \mathrm{g}$ of purified rEhBvac21 polypeptide mixed with Freund's adjuvant. Three bursts were applied via intraperitoneal at ten day intervals. Immune serum was collected seven days after the last immunization and used for Western blot assays. Mice were bleeding before immunization to use preimmune sera as a control in all experiments. For Western blot assays total protein extracts of induced bacteria or purified rEhBvac21 polypeptide were separated by $15 \%$ SDS-PAGE, transferred to nitrocellulose membranes, and blocked. This was followed by incubation with mouse anti-His monoclonal antibodies $(0.3 \mu \mathrm{g} / \mathrm{ml})$ (Roche) for $1 \mathrm{~h}$ at $37^{\circ} \mathrm{C}$, or by incubation with mouse polyclonal antirEhBvac2 1 antibodies $(1: 1,000)$ overnight at $4^{\circ} \mathrm{C}$. Then, membranes were washed and incubated with horseradish peroxidase-conjugated anti-mouse IgG secondary antibodies (Zymed) $(1: 1,000)$ for $3 \mathrm{~h}$ at $37^{\circ} \mathrm{C}$. Immunoreactive bands were revealed with 4-chloro-1-naphthol and $0.03 \%(\mathrm{v} / \mathrm{v}) \mathrm{H}_{2} \mathrm{O}_{2}$. For Western blot analysis of total trophozoite extracts and EhkO-enriched fraction, proteins were separated on 10\% SDS-PAGE. Then, membranes were incubated with anti-rEhBvac21 antibodies $(1: 20,000)$ for $3 \mathrm{~h}$ at $37^{\circ} \mathrm{C}$, and secondary antibodies $(1: 3,000)$ at $37^{\circ} \mathrm{C}$ for $1 \mathrm{~h}$. Positive bands were detected using the ECL Plus detection kit (Amersham) followed by exposure to X-ray films (Kodak).

\section{Immunofluorescence and confocal microscopy}

Trophozoites on prewarmed cover slips were fixed with $3 \%(\mathrm{w} / \mathrm{v})$ paraformaldehyde for $1 \mathrm{~h}$ at $37^{\circ} \mathrm{C}$, incubated with $50 \mathrm{mM} \mathrm{NH}_{4} \mathrm{Cl}$ for $1 \mathrm{~h}$ at $37^{\circ} \mathrm{C}$, permeabilized with $0.5 \%(\mathrm{v} / \mathrm{v})$ Triton $\mathrm{X}-100$ at $37^{\circ} \mathrm{C}$ for $30 \mathrm{~min}$ and blocked with $0.1 \%(\mathrm{w} / \mathrm{v}) \mathrm{BSA}$ in PBS at $37^{\circ} \mathrm{C}$ for $30 \mathrm{~min}$. Then, cells were incubated with mouse polyclonal antirEhBvac21 antibodies (1:80) for 2 h. Subsequently, cells were washed with PBS and incubated with FITC-labeled goat anti-mouse secondary antibodies (1:200) in blocking solution at $37^{\circ} \mathrm{C}$ for $2 \mathrm{~h}$. Finally, cells were washed and counterstained with $20 \mu \mathrm{g} / \mathrm{ml}$ PI (Fluka), and observed through a Leika NT-TCS confocal microscope. As a control, cells were incubated without the anti-rEhBvac21 antibodies.

\section{Phagocytosis assays}

Trophozoites were incubated with human RBCs at $37^{\circ} \mathrm{C}$ for different times (2 to $120 \mathrm{~min}$ ) as described [51]. At the end of the incubation times, the culture medium was removed and trophozoites were washed with PBS and fixed with $3 \%(\mathrm{w} / \mathrm{v})$ paraformaldehyde. For immunofluorescence experiments cells were treated as described before.

\section{Isolation of an EhkO-enriched fraction and V-ATPase activity assay}

EhkO-enriched fraction purification steps were carried out at $4{ }^{\circ} \mathrm{C}$ as described [50]. [ $\left.{ }^{3} \mathrm{H}\right]$-Thymidine labeled trophozoites were washed and resuspended in eight volumes of buffer A (10 mM HEPES pH 7.9, $10 \mathrm{mM}$ EDTA, and 10 $\mathrm{mM}$ DTT) containing protease inhibitors and $250 \mathrm{mM}$ sucrose. Cells were gently disrupted on ice using a Potter homogenizer and centrifuged at $160 \times \mathrm{g}$ for $10 \mathrm{~min}$. Then, the supernatant (nuclei-depleted fraction) was centrifuged at $10,000 \times \mathrm{g}$ for $10 \mathrm{~min}$ at $4^{\circ} \mathrm{C}$ in a JA-20 rotor (Beckman) to obtain the soluble fraction and the pellet. The latter was resuspended in $15 \%(\mathrm{v} / \mathrm{v})$ Nycodenz (Nycomed Pharma AS) in buffer A and top loaded on a Nycodenz discontinuous gradient (30, 40 and 50\%, v/v), which was centrifuged at $13,000 \times \mathrm{g}$ for $60 \mathrm{~min}$ at $4{ }^{\circ} \mathrm{C}$ in a SW40Ti rotor (Beckman). $0.5 \mathrm{ml}$ fractions were collected with a DensiFlow II C system (Buchler Instruments) and a RediFrac 1,000 fraction collector (Bio-Rad). $100 \mu \mathrm{l}$ of each fraction were $10 \%(\mathrm{w} / \mathrm{v})$ TCA precipitated and radioactivity content was determined in a LS6500 liquid scintillation counter (Beckman). EhkO enriched fractions were identified by its $\left[{ }^{3} \mathrm{H}\right]$-Thymidine incorporation.

The vacuolar ATPase activity was determined using a modification of the method described by Conibear and Stevens [16]. The sample was incubated in $50 \mathrm{mM} \mathrm{MES/Tris}$ buffer $\mathrm{pH} 6.9,5 \mathrm{mM} \mathrm{MgSO}_{4}$ and $5 \mathrm{mM} \mathrm{ATP}$ at $37^{\circ} \mathrm{C}$ for $16 \mathrm{~h}$. Some reactions were performed incubating some samples with $0.1 \mathrm{mM} \mathrm{Na}_{3} \mathrm{VO}_{4}$, or $300 \mathrm{nM}$ concanamycin 
A, or both. Released phosphate was determined by absorbance at $630 \mathrm{~nm}$ after a $15 \mathrm{~min}$ incubation period at RT with a mixture of $1 \%(\mathrm{w} / \mathrm{v})\left(\mathrm{NH}_{4}\right)_{6} \mathrm{Mo}_{7} \mathrm{O}_{24}, 4 \%(\mathrm{w} / \mathrm{v})$ $\mathrm{H}_{2} \mathrm{SO}_{4}, 1 \%(\mathrm{w} / \mathrm{v}) \mathrm{SDS}$ and $0.2 \%(\mathrm{w} / \mathrm{v})$ ascorbic acid.

\section{Authors' contributions}

All authors conceived the study. MGMH isolated and characterized the Ehvm2 gene, expressed the recombinant polypeptide in bacteria, obtained the anti-EhV-ATPase subunit B antibodies, purified EhkOs and performed the confocal microscopy studies. MLLB helped in RT-PCR assays and measurement of vacuolar ATPase activity. MGMH and JPLA performed the in silico analysis. EO and JPLA drafted the manuscript. All authors read and approved the final manuscript.

\section{Acknowledgements}

We thank CONACyT from Mexico for the financial support for this project.

\section{References}

I. Ackers JP, Mirelman D: Progress in research on Entamoeba histolytica pathogenesis. Curr Opin Microbiol 2006, 9(4):367-373.

2. Ravdin Jl: Amebiasis: Human Infection by Entamoeba histolytica. New York: John Wiley \& Sons Inc; 1988.

3. Beyenbach KW, Wieczorek $\mathbf{H}$ : The V-type $\mathbf{H}^{+}$ATPase: molecular structure and function, physiological roles and regulation. J Exp Biol 2006, 209:577-589.

4. Kane P: The where, when, and how of organelle acidification by the yeast vacuolar $\mathbf{H}^{+}$-ATPase. Microbiol Mol Biol Rev 2006, 70:177-191.

5. Nishi T, Forgac M: The vacuolar $\left(\mathbf{H}^{+}\right)$-ATPases-natures' most versatile proton pumps. Nat Rev Mol Cell Biol 2002, 3:94-103.

6. Sun-Wada GH, Wada $Y$, Futai M: Diverse and essential roles of mammalian vacuolar-type proton pump ATPase: toward the physiological understanding of inside acidic compartments. Biochim Biophys Acta 2004, I658: 106-I I 4.

7. Hurtado-Lorenzo A, Skinner M, El Annan J, Futai M, Sun-Wada GH, Bourgoin S, Casanova J, Wildeman A, Bechoua S, Ausiello DA, Brown $D$, Marshansky V: V-ATPase interacts with ARNO and Arf6 in early endosomes and regulates the protein degradative pathway. Nature Cell Biol 2006, 8: I24-I36.

8. Löhden-Bendinger $U$, Bakker-Grunwald T: Evidence for vacuolar type proton ATPase in Entamoeba histolytica. Z Naturforsch [C] 1990, 45(3-4):229-232.

9. Yi Y, Samuelson J: Primary structure of the Entamoeba histolytica gene (Ehvmal) encoding the catalytic peptide of a putative vacuolar membrane proton-transporting ATPase (VATPase). Mol Biochem Parasitol 1994, 66:165-169.

10. Descoteaux S, Yu Y, Samuelson J: Cloning of Entamoeba genes encoding proteolipids of putative vacuolar proton-translocating ATPases. Infect Immun 1994, 62(8):3572-3575.

II. Okada M, Huston C, Mann B, Petri W, Kita K, Nozaki T: Proteomic analysis of phagocytosis in the enteric protozoan parasite Entamoeba histolytica. Eukaryotic Cell 2005, 4:827-83I.

12. Okada M, Nozaki T: New insights into molecular mechanisms of phagocytosis in Entamoeba histolytica by proteomic analysis. Arch Med Res 2006, 37:244-252.

13. Futai $M$, Iwamoto $A$, Omote $H$, Maeda M: A glicine-rich sequence in the catalytic site of F-type ATPase. J Bioenerg Biomembr 1992, 24:463-467.

14. Vasilyeva E, Forgac M: 3-O-(4-Benzoyl) benzoyladenosine 5-triphosphate inhibits activity of the vacuolar $\left(\mathrm{H}^{+}\right)$-ATPase from bovine brain clathrin-coated vesicles by modification of a rapidly exchangeable, noncatalytic nucleotide binding site on the B subunit. J Biol Chem 1996, 27I: 12775-12782.

15. Orozco E, Gharaibeh R, Riverón AM, Delgadillo DM, Mercado M, Sánchez T, Gómez Conde E, Vargas MA, López-Revilla R: A novel cytoplasmic structure containing DNA networks in Enta- moeba histolytica trophozoites. Mol Gen Genet 1997, 254:250-257.

16. Conibear E, Stevens TH: Studying yeast vacuoles. Methods Enzymol 2002, 35 I:408-432.

17. Loftus B, Anderson I, Davies R, Alsmark UC, Samuelson J, Amedeo P, Roncaglia P, Berriman M, Hirt RP, Mann BJ, et al:: The genome of the protist parasite Entamoeba histolytica. Nature 2005, 433(7028):865-868.

18. Aley S, Cohn Z, Scott W: Endocytosis in Entamoeba histolytica. J Exp Med 1984, 160:724-737.

19. Ghosh S, Field J, Rogers R, Hickman M, Samuelson J: The Entamoeba histolytica mitochondrion-derived organelle (crypton) contains double-stranded DNA and appears to be bound by a double membrane. Infect Immun 2000, 68:4319-4322.

20. Smardon A, Tarsio M, Kane P: The RAVE Complex is essential for stable assembly of the yeast V-ATPase. J Biol Chem 2002, 277: $1383 \mid-13839$.

21. Smardon A, Kane P: RAVE is essential for the efficient assembly of the $\mathbf{C}$ subunit with the vacuolar $\mathbf{H}^{+}$-ATPase. I Biol Chem 2007, 282:26185-26194.

22. Peters C, Bayer MJ, Buhler S, Andersen JS, Mann M, Mayer A: Transcomplex formation by proteolipid channels in the terminal phase of membrane fusion. Nature 200I, 409:58I-588.

23. Qi J, Forgac M: Cellular environment is important in controlling V-ATPase dissociation and its dependence on activity. J Biol Chem 2007, 282:24743-2475I.

24. Moriyama Y, Hayashi M, Yatsushiro S, Yamamoto A: Vacuolar proton pumps in malaria parasite cells. J Bioenerg Biomembr 2003, 35:367-375.

25. Solís F, Orozco E, Córdova L, Rivera B, Luna-Arias JP, Gómez-Conde E, Rodríguez MA: Entamoeba histolytica: DNA carrier vesicles in nuclei and kinetoplast-like organelles (EhkOs). Mol Genet Genomics 2002, 267:622-628.

26. Luna-Arias JP, Hernández-Rivas R, de Dios-Bravo G, Garcia J, Mendoza L, Orozco E: The TATA-box binding protein of Entamoeba histolytica: cloning of the gene and location of the protein by immunofluorescence and confocal microscopy. Microbiology 1999, I45:33-40.

27. Marchat LA, Gómez C, Pérez DG, Paz F, Mendoza L, Orozco E: Two CCAAT/enhancer binding protein sites are cis-activator elements of the Entamoeba histolytica EhPgpl (mdr-like) gene expression. Cell Microbiol 2002, 4:725-737.

28. Mendoza L, Orozco E, Rodríguez MA, García-Rivera G, Sánchez T, García E, Gariglio P: Ehp53, an Entamoeba histolytica protein, ancestor of the mammalian tumour suppressor p53. Microbiology 2003, I 49:885-893.

29. Rodriguez MA, Garcia-Perez RM, Mendoza L, Sanchez T, Guillen N, Orozco $E:$ The pyruvate:ferredoxin oxidoreductase enzyme is located in the plasma membrane and in a cytoplasmic structure in Entamoeba. Microb Pathog 1998, 25: I-I0.

30. Mai Z, Ghosh S, Frisardi M, Rosenthal B, Rogers R, Samuelson J: Hsp60 is targeted to a cryptic mitochondrion-derived organelle ("crypton") in the microaerophilic protozoan parasite Entamoeba histolytica. Mol Cell Biol 1999, 19:2198-2205.

31. Tovar J, Fischer A, Clark CG: The mitosome, a novel organelle related to mitochondria in the amitochondrial parasite Entamoeba histolytica. Mol Microbiol 1999, 32:1013-1021.

32. Tovar J, León-Avila G, Sánchez L, Sutak R, Tachezy J, Giezen M van der, Hernández M, Müller M, Lucocq JM: Mitochondrial remnant organelles of Giardia function in iron-sulphur protein maturation. Nature 2003, 426: $172-176$.

33. Giezen $M$ van der, Tovar J, Clark CG: Mitochondrion-derived organelles in protists and fungi. Int Rev Cytol 2005, 244: 175-225.

34. Giezen $M$ van der, Tovar J: Degenerate mitochondria. EMBO Rep 2005, 6:525-530.

35. Leon-Avila G, Tovar J: Mitosomes of Entamoeba histolytica are abundant mitochondrion-related remnant organelles that lack a detectable organellar genome. Microbiology 2004, 150: 1245-1250.

36. McLaughlin J, Lindmark D, Müller M: Inorganic pyrophosphatase and nucleoside diphosphatase in the parasitic protozoon, Entamoeba histolytica. Biochem Biophys Res Comm 1978, 82:913-920.

37. Clarke M, Köhler J, Arana Q, Liu T, Heuser J, Gerisch G: Dynamics of the vacuolar $\mathrm{H}^{+}$-ATPase in the contractile vacuole com- 
plex and the endosomal pathway of Dictyostelium cells. J Cell Sci 2002, I I 5:2893-2905.

38. Saito-Nakano Y, Yasuda T, Nakada-Tsukui K, Leippe M, Nozaki T: Rab5-associated vacuoles play a unique role in phagocytosis of the enteric protozoan parasite Entamoeba histolytica. J Biol Chem 2004, 279:49497-49507.

39. Nozaki T, Nakada-Tsukui K: Membrane trafficking as a virulence mechanism of the enteric protozoan parasite Entamoeba histolytica. Parasitol Res 2006, 98: 179-183.

40. Holliday LS, Bubb MR, Jiang J, Hurst IR, Zuo J: Interactions between vacuolar $\mathrm{H}^{+}$-ATPases and microfilaments in osteoclasts. J Bioenerg Biomembr 2005, 37:4 I 9-423.

41. Ohira M, Smardon AM, Charsky CM, Liu J, Tarsio M, Kane PM: The $E$ and $G$ subunits of the yeast $V$-ATPase interact tightly and are both present at more than one copy per $V_{1}$ complex. Biol Chem 2006, 281:22752-22760.

42. Strompen G, Dettmer J, Stierhof YD, Schumacher K, Jurgens G, Mayer U: Arabidopsis vacuolar H-ATPase subunit E isoform I is required for Golgi organization and vacuole function in embryogenesis. Plant J 2005, 4 I: I25-I32.

43. Kawamura $Y$, Arakawa K, Maeshima M, Yoshida S: Tissue specificity of $E$ subunit isoforms of plant vacuolar $\mathrm{H}^{+}$-ATPase and existence of isotype enzymes. J Biol Chem 2000, 275:65 I 5-6522.

44. Kawasaki-Nishi S, Bowers K, Nishi T, Forgac M, Stevens TH: The amino-terminal domain of the vacuolar proton-translocating ATPase a subunit controls targeting and in vivo dissociation, and the carboxyl-terminal domain affects coupling of proton transport and ATP hydrolysis. J Biol Chem 200I, 276:474II-20.

45. Wassmer T, Kissmehl R, Cohen J, Plattner H: Seventeen a-subunit isoforms of Paramecium V-ATPase provide high specialization in location and function. Mol Biol Cell 2006, 17:917-930.

46. Mazzuco A, Benchimol M, De Souza W: Endoplasmic reticulum and Golgi-like elements in Entamoeba. Micron 1997 28:24I-247.

47. Dacks JB, Davis LA, Sjögren AM, Andersson JO, Roger AJ, Doolittle WF: Evidence for Golgi bodies in proposed 'Golgi-lacking' lineages. Proc Biol Sci 2003, 270(SuppI 2):SI68-SI7I.

48. Bredeston LM, Caffaro CE, Samuelson J, Hirschberg CB: Golgi and endoplasmic reticulum functions take place in different subcellular compartments of Entamoeba histolytica. J Biol Chem 2005, 280:32168-32176

49. Diamond LS, Harlow R, Cunnick C: A new medium for the axenic cultivation of Entamoeba histolytica and other Entamoeba. Trans R Soc Trop Med Hyg 1978, 72:43I-432.

50. Luna-Arias JP, Sanchez T, Herrera-Aguirre ME, Chavez P, Orozco E: Purification of Entamoeba histolytica DNA containing organelles (EhkOs): a further characterization. J Eukaryot Microbiol 2003, 50(Suppl):706-708.

5I. García-Rivera G, Rodríguez MA, Ocádiz R, Martínez-López MC, Arroyo R, González-Robles A, Orozco E: Entamoeba histolytica: a novel cysteine protease and an adhesin form the $112 \mathrm{kDa}$ surface protein. Mol Microbiol 1999, 33:556-568.
Publish with Bio Med Central and every scientist can read your work free of charge

"BioMed Central will be the most significant development for disseminating the results of biomedical research in our lifetime. "

Sir Paul Nurse, Cancer Research UK

Your research papers will be:

- available free of charge to the entire biomedical community

- peer reviewed and published immediately upon acceptance

- cited in PubMed and archived on PubMed Central

- yours - you keep the copyright
BioMedcentral 